\title{
Migration and Transcultural Aspect of Sexual Abuse of Children and Adolescents
}

\section{Jan Ilhan Kizilhan*}

Department of Transcultural Psychosomatic, Cooperative State University Baden-Württemberg, Institute for Psychotherapy and Psych traumatology, VillingenSchwenningen, Germany

*Corresponding author: Jan Ilhan Kizilhan, Department of Transcultural Psychosomatic, Cooperative State University Baden-Württemberg, Institute for Psychotherapy and Psych traumatology, Villingen-Schwenningen, Germany, Tel: +497113206600; E-mail: kizilhan@dhbw-vs.de

Rec date: November 10, 2017; Acc date: December 08, 2017; Pub date: December 11, 2017

Copyright: (c) 2017 Kizilhan Jl. This is an open-access article distributed under the terms of the creative commons attribution license, which permits unrestricted use, distribution, and reproduction in any medium, provided the original author and source are credited.

\begin{abstract}
Sexual abuse toward children and adolescents is a global public health and human rights concern. Despite being a crime in most countries, and with well-known physical and mental health consequences, the majority of sexual offences are not reported. Child and adolescents sexual abuse is a maltreatment form characterized by contact or noncontact acts perpetrated by adults or older children toward younger children who have little power to resist. This overview aims to understand the social context of child sexual abuse, and the perceived roles of parents, community, and key professionals in handling such incidents of children and adolescents with a migration background.
\end{abstract}

Keywords: Sexual abuse; Migration; Child and adolescents; Intervention and prevention

\section{Introduction}

Sexual abuse of dependents, particularly of children, is a taboo subject in the majority of societies [1]. However, it is an issue which has always preoccupied us, in every culture with differing prevalence rates, explanations of the causes and the manner in which it should be handled [2-4].

Whereas research and the public have increasingly addressed this issue in the Western world in the last thirty years, this same interest is not to be observed in non-industrialized countries and the Islamic world [5]. The reaction of the population, social institutions and health profession in, for example, Iran, to a degree in Turkey, in Arabic countries, India or even former Soviet republics bear witness - with a few exceptions - indicates attitudes ranging from little interest in the suffering of victims to a hostile rejection of those affected [6-8]. With the global migration in the last decades and the ethnic, religion and national and international conflicts like war and flights in Iraq and Syria the risk of many forms of violence increased [9]. For this and another reason people are forced to flight from their homeland to a different country in the world. Women and girls, travelling alone or female headed households with children are particularly vulnerable to sexual violence $[10,11]$.

A study in 2014 estimated that around $21 \%$ of women in 14 conflict countries reported sexual violence [12]. Refugee child and women are affected by sexual violence not only in areas of conflict but also on their journey to and once they arrive in western countries [13]. Their cultural perceptions of family and religion, individual biographies and migration histories possibly make it difficult for them to confront the issue of the sexual abuse of children and adolescents, both in public and in institutions. This makes it difficult to develop and implement concepts for prevention and intervention [13].
We therefore wish to provide an overview in this article of migration and its causes, the psychosocial situation of different migration generations and the issue of the sexual abuse of children and adolescents with a migration background, along with a picture of prevalence rates and options for prevention and intervention. As the majority of people with a migration background in Europe has a Muslim background (according to information approximately 7 million Muslims live in Europe), the focus of our attention in this article is the (inter)cultural factors of sexual abuse among people with an Islamic background [14].

\section{Migration}

Migration not only entails an environmental transition from one place of residence to another, but also a change in external living conditions, the working and accommodation environment and associated social and cultural changes [15]. The effects of this are not only governed by the extent of change. The causes of migration (war, ethnic and religious conflicts, oppression of democratic movements, environmental exploitation, flight and trauma, natural catastrophes and epidemics, international economic globalization, poverty and cultural conflicts, etc.) and individual controllability of these factors play an important role in this respect [16].

Biographic change influences both individual and collective identity, the manner in which the past is dealt with and adaptation in the host country to a considerable degree [17]. How this new life phase is shaped depends on individual and collective coping mechanisms and the options to avail of social networks [18]. The building of a new relationship network in another cultural, ethnic and social context demands new social resources, a completely new orientation and a new competence to take necessary actions $[19,20]$.

Migration can therefore be regarded as a life event complex encompassing numerous interlinked factors and processes specific to migration (changes, demands and permanent strains) and which, among other things, depends on the nature and type of migration [16]. 
Refugees generally migrate due to coercion or out of political necessity. Many adult refugees and children in this context have been exposed to numerous burdens such as war, torture and flight, sexual violence and abuse [13].

\section{Family Structure}

People from traditional family-oriented societies in particular experience considerable stress at the beginning of their stay in the migration countries of the western world's [20]. In contrast to an individualistic society, a traditional society binds the individual strongly into a group structure which, on the one hand, provides protection but, on the other, demands a high degree of loyalty $[21,22]$.

People from traditional rural regions are generally characterized by a collective mind-set in which the personal wishes, interests and complaints of an individual member are regarded as secondary. Harmony and security within the family and peer group are considerably more important than individual autonomy [23]. The individual regards him or herself as part of a solidarity community from which corresponding tasks and obligations arise. His or her main purpose is to ensure that the solidarity community, and in particular the core and extended family, is not prejudiced or harmed in any way. It is therefore logical that personal feelings and complaints should not be expressed to prevent any possible burden or harm to the family [24]. Hence, relationship structures exist in traditional families which involve strong interpersonal bonds characterized by deeply collectivist values [23]. As in all rural communities in Southern Europe and Asia Minor, the family represents a reliable and effective protective association in Turkish society. Internal family cohesion is developed to a far greater degree than in Western European families and acts as an orientation benchmark in times of great psychological, psychosocial or economic stress.

However, family support is not always the equivalent of emotional and instrumental support [25]. During the course of adaptation to the new living conditions in the host country, family roles are frequently redistributed, leading to intergenerational conflicts which place a burden on family relationships [26-28].

Customs, values, rules and standards are put to the test in the new environment, and new ways need to be found to deal with these. Persistent ambivalence and discord can be the consequences [27]. For many people, migration also means at least a temporary separation from that part of the family left behind in the home country and from acquaintances, friends and supportive social networks [20].

\section{Sexual Abuse of Children and Adolescents with a Migration Background}

When there is a danger of being ostracized by one's own social community, sexual abuse as a child and, frequently, also as an adult is often impossible to deal with. Feelings of guilt and shame, such as perceptions of responsibility for the abuse, lack of honor, and loss of self-worth, influence disclosure [29].

The concealment of sexual abuse in traditional cultures (e.g. in Islamic cultures, due to specific religious beliefs regarding sexuality) can contribute to the development of psychological illnesses as, among other reactions, sanctions and social exclusion can be expected. Hence, according to Islamic belief, it is the duty of a woman to enter into matrimony as a virgin. Virginity is equated with the integrity of the hymen. Anything else would offend the honour of her family. As a consequence, many young girls and women often conceal an abuse of this nature. The fear of being ostracized by one's own family makes it difficult for those affected to confide in a family member or even a stranger, whether male or female [30].

Some children still suffer from depression, trauma and personality disorders with a risk of suicide many years after the abuse has taken place. For example [22] established that, in addition to a trauma disorder, young migrant girls developed an obsession with washing following a rape, because they considered their bodies to be unclean and, consequently, spent several hours every day cleaning it [31]. One reason among others for this behaviour was that the girls had learnt as children to perform certain rituals, including washing, prior to daily prayers, as prescribed in Islam. The dysfunctional conviction that the body is unclean reinforces this [32].

\section{Shame and Guilt Culture in Islam}

To the Western mind, guilt can be understood to be an action or behavior which is perceived as unjust. The event or occurrence itself induces feelings of guilt, regardless of the nature of the relationship between the perpetrator and victim. An admission of guilt and, where possible, redress may ensue as compensation for perceived guilt [33].

In addition to the act itself, the possible loss of face in the community in particular plays a significant role in a shame culture. The victim can, for example, develop a high level of shame following an incident of sexual abuse because, firstly, he or she was not in a position to prevent it and, secondly, this abuse results in the victim's own family appearing weak in the eyes of the community because it was not able to protect the victim. The feeling of having put the family in a difficult situation as a consequence leads to feelings of perceived "disgrace" and, not least, also to suicide or suicide attempts by the victims.

That which is regarded as appropriate behavior is not decided by the individual in the shame culture, but by the community. For this reason, the thoughts and deeds of an individual are always linked to the question of the significance and consequences this can entail for his or her community [33]. The culture is characterized by this group orientation and, as a consequence, so is relationships, the interaction with others, the shaping of conflict and psychological processing mechanisms.

In the guilt culture, different individual behavior is more likely to be tolerated than in shame cultures, even if it is inappropriate from a cultural point of view. Shame cultures regard a possible individual transgression of prescribed standards as an affront to the community [33-35].

In addition to psychosomatic ailments which are depicted and experienced differently, depending on the specific culture $[20,26]$, studies have also reported symptoms such as pains afflicting the head, throat, stomach and lower abdomen without discernible organic causes in children without a migration background. Eating and sleep disorders, speaking difficulties, choking seizures and speech disorders may also be involved. Sexually abused children who still live in the family with the perpetrator (male or female) suffer particularly severely from sleep disorders and nightmares, as the abuse here primarily occurs at night [36].

From an overall societal and political point of view, increasing incidents of violence motivated by racism are a further aspect which should be taken into consideration [37]. However, empirical data on a correlation between sexual violence and violence motivated by racism 
has not yet been compiled to an adequate degree. In war zones, such as in African and Asian countries, but also during the war in former Yugoslavia, sexual violence was in part perpetrated against children by military and paramilitary units in a systematic fashion [36].

Simultaneously, the sexual abuse of children also appears to be an overall societal problem, as indicated by examples in India which include the case of a young woman in 2012 who was raped by several men on a bus, an incident which has captured wide public attention. The latest study from Human Rights Watch (2013) assumes that 7,200 children are raped in India every day, but the number may be considerably higher.

\section{Prevalence and Indication Rates}

In meta-analyses, which included data from 331 studies representing nearly 10 million individuals could show that the prevalence of sexual abuse was $11.8 \%$, with $7.6 \%$ of males and $18 \%$ of females. In this analysis, Asia reported the lowest combined prevalence for both boys and girls, while Africa had the highest prevalence for boys and Australia the highest prevalence for girls.

Special studies on prevalence and indication rates of sexual child abuse among migrants of both sexes have to date not been conducted. However, in a representative sampling of 11,428 individuals all over Germany aged between 16 and 40, migrants of both sexes were also asked if they had been victims of different crimes and, in particular, sexual abuse [38]. In this study, almost $20 \%$ of those surveyed had a migration background (10.1\% Turkish, 9.6\% Russian).

In the case of those individuals with a migration background, it is noticeable that, in comparison to the sampling of Germans, reports of experiences of abuse among women with a Turkish migration background are, in particular, considerably fewer. Whereas, for example, $7.3 \%$ of the German women reported abuse with physical contact up to the age of 16 , this was only admitted by $1.7 \%$ of the Turkish women. The value for women with a Russian migration background was $6.5 \%$ (Table 1). The Russian women had been victims of exhibitionist acts before the age of 16 more than 1.5 times as often as those women without a migration background surveyed [38]. In a comparison of all abuse categories, women with a Turkish migration background are most rarely affected by sexual abuse. $3.4 \%$ of these had experienced at least one form of sexual abuse, whereas this applied to $10.2 \%$ of those surveyed without a migration background and $12.2 \%$ with a Russian migration background. The number of male individuals in all three groups is considerably less when compared to female individuals.

\begin{tabular}{|l|l|l|l|l|l|l|}
\hline Variables & \multicolumn{2}{|l|}{$\begin{array}{l}\text { No migration } \\
\text { background }\end{array}$} & \multicolumn{2}{|l|}{$\begin{array}{l}\text { With } \\
\text { migration } \\
\text { background }\end{array}$} & \multicolumn{2}{|l|}{$\begin{array}{l}\text { Turkish } \\
\text { With Russian } \\
\text { migration } \\
\text { background }\end{array}$} \\
\hline $\begin{array}{l}\text { Acc. to Bienek } \\
\text { et al. }\end{array}$ & $\begin{array}{l}\text { Femal } \\
\text { es }\end{array}$ & Males & Females & Males & $\begin{array}{l}\text { Female } \\
\text { s }\end{array}$ & Males \\
\hline $\begin{array}{l}\text { Victims of } \\
\text { hands-on acts }\end{array}$ & $7.3 \%$ & $1.2 \%$ & $1.7 \%$ & $0.7 \%$ & $6.5 \%$ & $1.2 \%$ \\
\hline $\begin{array}{l}\text { Victims of all } \\
\text { abuse } \\
\text { categories }\end{array}$ & $10.2 \%$ & $2.3 \%$ & $3.4 \%$ & $1.2 \%$ & $12.2 \%$ & $2.2 \%$ \\
\hline
\end{tabular}

Table 1: Prevalence and indication rates of sexual child abuse among migrants of both sexes.
Whether the comparatively low prevalence rate of sexual abuse among those surveyed of Turkish origin can be related to the fact that, due to traditional cultural perceptions of "honour" and possibly the fear of being ostracized by their own family and the Turkish community, they have a higher inhibition threshold and sense of shame about admitting to this experience in a questionnaire is an aspect that deserves discussion [39]. Whether other factors (e.g. unfamiliarity with questionnaires) could be the cause of any possible reticence on the part of those surveyed is another question which cannot be answered conclusively. A further consideration is that this group is also probably exposed to fewer risk situations outside the family, due to the strict supervision of and close relationship to the family, and this would explain the low prevalence of abuse with physical contact of women of Turkish origin outside the family.

However, there are indications that perpetrators are not named within the immediate family because of the reasons already described. Many of the victims are married within the extended family (e.g. female cousins to male cousins, etc.) and therefore remain under the control of the collective without any possibility of professional helpers (of both sexes) gaining access to them [40].

High-risk sexual abuse groups include in particular unaccompanied underage refugees, children of illegal immigrants and children from war zones who, in their home country, while fleeing and, also, in the host country have no significant protection and rapidly become victims of sexual abuse $[39,41]$.

\section{Prevention and Intervention}

\section{Prevention}

Prevention aims to prevent sexual violence through appropriate measures. There is no sure method of protecting a child, but favourable educational influences can aid prevention. These should also take specific cultural aspects into consideration when working with individuals with a migration background [42].

Prevention primarily means focusing on families, schools, the social environment (e.g. migrant associations and mosque communities) and the political sphere. Special programmes in kindergartens and schools could address culturally sensitive issues such as religion, the role of the family and ways in which children could confide in their child care workers and teachers of both sexes. It should be explicitly emphasized in this respect that sexual abuse of children can be perpetrated by one's own family members but, at the same time, measures should be taken to avoid unsettling parents and children. The primary focus, however, should be on strengthening children in terms of their rights and competences and their self-confidence in exerting these [43]. Taking specific cultural aspects of the family structure into account, consideration should be given to whether, in addition to children and parents, older sisters could, for example, be involved, because they probably have an adequate mastery of the German language, are socialized in Germany and, in addition, are more likely to be a partner in which their younger sisters will confide more readily than in their own mother, as they do not wish to cause sadness to the latter and because they fear punishment, etc. Moreover, they frequently have a greater knowledge of sexuality than their parents who, possibly, have themselves never been adequately enlightened or, due to their traditional upbringing, rarely speak about sexuality with their children.

Strong family cohesion and possible "family secrets" make it difficult for children to speak to strangers - including child carers of both sexes 
and teachers. Issues such as guilt, shame, sexuality and the fact that adults, including the parents, are not permitted to violate the rights of children should be discussed with children and their family members, particularly the parents. This approach should also involve the addressing of violence against children, but also domestic violence, as structural violence, war and the glorification of violence in the media still exist in many countries from which migrants of both sexes originate, and violence can also be regarded as a method of education in such countries [44].

It is important during this initial step that state assistance systems, institutions oriented towards specific cultures, professional helpers, education, multiplicators of both sexes with a migration background and, possibly, migrant associations be involved, both in the overall strategy and with each other. Information material in different languages is also necessary for parents and those affected who have an inadequate knowledge of the German language. Seminars and workshops from migrant associations and state institutions involving experts of both sexes, children and their families are particularly effective in terms of prevention. Child carers, teachers and other professionals of both sexes involved in these measures should be trained with an adequate sensitivity towards cultural questions [45].

Appropriate perpetrator therapy programmes designed to prevent further abuse are also part of initial preventive measures. However, the primary objective is to enable girls and boys to protect themselves against sexual abuse [46].

A further step aims to detect existing abuse in good time and bring it to an end. Interventions contribute in this respect and help those affected to deal with the experience of sexual abuse in the long term.

Only where these measures are not effective and children have already been victims of sexual abuse is it necessary to alleviate the consequential damage through counselling and treatment. Children should be helped insofar as they are enabled to deal with these traumatic incidents and allow them to shape their lives in a reasonably satisfactory manner.

\section{Intervention}

Intervention measures involving an adequate knowledge of the cultural background should ensure that concrete cases of sexual abuse are terminated as quickly as possible. In addition to moderating and insofar as possible - offsetting the negative consequences for the victim, meaning those children and adolescents affected and family members not involved in abuse, they should also counteract later revictimisation. Perpetrators of both sexes should be prevented from committing further acts.

Naturally enough, intervention can only be effective if culturally sensitive assistance systems exist and if those affected are aware of and can take advantage of these. In the case of children and adolescents with a migration background in particular, careful evaluation would indicate that this is only the case to a very limited degree. Even gaining access to migrant families with traditional perceptions and beliefs is extremely difficult. As already explained, sexual abuse may be concealed to "protect the collective" and due to the fear of being ostracised. Parents forbid their children to speak about it. During medical examinations of, for example, incessant abdominal pains, or conducted later due to behavioural disorders (aggression, self-inflicted injuries, depression, anxiety, etc.), the reasons for these ailments are not mentioned [39].
During counselling and therapy discussions, the use of interpreters of both sexes may be necessary, due to limited knowledge of German. However, these should not come from the same social community because, firstly, the family is ashamed to talk about the issue and, secondly, interpreters, both male and female, could possibly pass on this information to others. In addition, the interpreter should be trained to translate technical terms used by doctors and therapists which do not exist in the respective foreign languages. Interpreters do not receive any remuneration in many areas of the German counselling and health system.

Children and adolescents with a migration background who have been born and grown up in Germany generally speak German well and, when approached with adequate cultural sensitivity and appropriate tools, profit from therapy.

\section{Discussion}

\section{Cultural aspects in psychotherapeutic treatment}

Regardless of the culture or generation patients of both sexes come from, the fundamental principles of effective psychotherapy are, irrespective of these factors, always the same and encompass empathy, appreciation and a fundamentally open attitude on the part of those involved in treatment and counselling. This applies to both children and adults.

Those involved in treatment are traditionally regarded as a motherly or fatherly friend of the family. They represent a figure of authority who cultivates an active, knowledgeable and counselling acquaintance with the male or female patient and his or her family. The psychotherapist should accept this "cultural transfer" if, for example, he or she wishes to avoid provoking considerable insecurity. In contrast to indigenous patients of both sexes, where the mobilizing of one's own potential is paramount, this patient group expects greater help from the authority, and this should be offered. However, this means that the psychotherapist also needs to develop an awareness of his or her own cultural identification. He or she should be capable of appreciating his or her own capacity to engage in this transfer with the patient (whether male or female) and discerning his or her individual and social prejudices and stereotypes which arise as collective transfers, neutralising these in as far as possible before they have a destructive effect during treatment. Only after this is it possible to encourage a readiness on the part of the male or female patient to achieve a behavioural change on a psychological and physical level.

Effective counselling and treatment also involves the precise analysis of problem behaviour, the development of an explanatory model and the definition of common goals. However, there is a particular need in the case of clients of both sexes with a migration background to demonstrate intercultural competence and a "culturally sensitive" approach to avoid misunderstandings and irritation.

In the case of individuals with a traditional orientation, it is important to respect their special cultural traits in this context right from the outset of treatment and counselling when, for example, it is necessary to explain the correlations between body and mind. For instance, physical ailments should not be simply reduced to psychological conflicts, even where it is known that the patient frequently complains of non-specific symptoms. Children and adolescents in particular among the victims of abuse from other cultures frequently complain of diffuse and ambiguous abdominal pains without mentioning abuse. 


\section{The sense of shame and physical integrity in Islam}

The Islamic faith inculcates an understanding of physical integrity and intimacy based on a strong sense of shame which has moral and practical implications for the lives of individuals. This results in a desire to cover the body in a special manner, to protect oneself from the gaze of others and avoid physical contact with non-relatives and unmarried members of the opposite sex (cf. Sure 24/30-31, Sure 33/59). A woman is obliged to cover the entire body almost completely, with exceptions only being made for the hands, feet and face.

The sense of shame possibly also influences individual decisions and behaviour during counselling and treatment, with, for example, the sex of the doctor or therapist assuming an important role.

A case of illness represents an emergency situation in many respects, but this also applies to the search for support and help, particularly in the case of sexual abuse of children and adults. This leads to the possibility of a partial or temporary suspension of the Islamic rules which otherwise apply in daily life. Professional helpers of both sexes should take advantage of this in the interest of male and female clients.

It is imperative that physical ailments which occur frequently be taken seriously, and the application of medical diagnostics which, fundamentally speaking, follow the principles of somatic medicine is also important for the self-perception of patients of both sexes and imparting to them a sense that they are being taken seriously. Simultaneously, in the case of an obviously reactive or psychosomatic background, one should avoid the hopeless path of the never-ending and, equally, encumbering instrument-based diagnostics of modern medicine. Instead, treatment professionals should endeavour to find an honorable retreat from the symptomatology which is reconcilable with the illness concept of the patient, whether male or female. Positive experience in cases of dissociative paralysis has been gained with, for example, the suggestive use of physiotherapy and appropriate exercise treatments. Similar success has been achieved through relaxation techniques in different pain symptomatology cases.

However, the parents of affected children are primarily responsible for bewailing the distress of the victims and, for example, mix the suffering of the child with family difficulties and cares. Therefore, a generous portion of patience is often required if correlations are to be understood, the subjective view of the parents appreciated and to win their cooperation over in order to offer effective help to the client, whether male or female. A recapitulation of the migration history of the family realized together in advance generally makes this easier.

Misunderstandings may also arise out of different perceptions regarding, for example, the approach to therapy. The parents or legal guardians of affected children from traditional societies are often unfamiliar with the idea of working together with the therapist and, possibly, the child to develop a model for explaining ailments and involvement in treatment. Instead, they tend rather to expect the professional helper to identify the reasons for ailments and illustrate different assistance options. It is therefore even more important to explain the type of and procedure involved in support or treatment right at the outset. Clients value characteristics such as understanding and patience, politeness and candidness more than the specialized knowledge of a counsellor or therapist of either sex. Counsellors or therapists of both sexes should take the need for harmony into account and demonstrate respect for the family hierarchy, without compromising their professionalism. The central role of the family should, in particular, be taken into consideration with regard to the first generation.

Another important issue is the fact that the German health system still demonstrates deficiencies in the degree to which it has adapted to the needs of individuals with a migration background [43]. These deficiencies include the absence of treatment and counselling services which address the needs of native languages and specific cultural aspects. In particular, children and adolescents from war zones who have been traumatized to a complex degree, including as a result of sexual abuse, require trained interpreters of both sexes who can cooperate with male and female trauma therapist and counsellors in an atmosphere characterized by cultural sensitivity [44].

\section{Conclusion and Considerations}

\section{Considerations of specific cultural aspects during therapy}

\section{Medical and psychotherapeutic aspects}

During initial contact, ailments reported by clients of both sexes can be limited to physical pains and characterized by a fixation on these. The existence of possible psychological conflicts and stress can be initially rejected or denied. Limited knowledge of the German language can complicate the anamnesis.

The feeling of not been taken seriously enough with regard to ailments can even strengthen the fixation on these (e.g. multiple, recurrent, fluctuating physical symptoms experienced on changing bodily organs). Abdominal pains are not only encountered frequently among children, but also afflict adults.

A comorbidity with other psychosocial ailments is frequently encountered. Many clients of both sexes fail to identify a possible correlation between disorders, or have up until now not been adequately informed about these.

Psychoeducative measures and information on sexual abuse, violence, prevention and intervention should be adapted to the culture of origin of male and female clients and made available to them.

The involvement of family members can be important for both diagnosis and the treatment and counselling process with regard to resources, family dynamics, etc. The family can be involved in a supportive role during treatment and counselling when it comes to improving skills in the sense of social competence and resources.

Treatment through medication, operations or physiotherapy measures can, from the point of view of the male/female client or the parents of the children, appear to be initially adequate.

\section{Social aspects}

- Linguistic problems (language barriers, the use of male/female interpreters and payment by health insurance providers)

- Adequate knowledge of differences of a cultural nature (e.g. the role of family members in collective societies)

- Improvement of psychological problems specifically related to migration (generation conflicts, integration, etc.)

- Improved rights in host societies (e.g. restricted living space, minimum financial

support of unaccompanied refugee children and adolescents) 
- Facilitating of family reunification (particularly where children are involved who have already been exposed to warlike or structural threats and violence in the country of origin or another state).

\section{General provision structures}

- Timely initial identification of vulnerable male/female clients.

- The offering of a basic range of psychosocial services (counselling, low-threshold service offer) for children and adolescents suffering from psychological stress, but also adult victims of sexual violence.

- The provision of psychotherapy and counselling services by persons with special knowledge and skills.

- Treatment professionals and counsellors of both sexes trained in the mother tongue with the undertaking of diagnostics suited to the specific culture.

- Improvement of treatment options for children and adolescents of traumatized refugees without residence security within regular health care structures.

- Psychiatric and psychosomatic clinics with adequate transcultural competence.

\section{References}

1. Elliott M (1994) Female sexual abuse of children: 'the ultimate taboo'. JR Soc Med 87: 961-964.

2. Collin-Vézina D, Daigneault I, Hébert M (2013) Lessons learnt from child sexual abuse research: Prevalence, outcomes and preventive strategies. Child Adolesc Psychiatry Mental Health 7: 22.

3. Murray L, Ngyuen A, Cohen JA (2014) Child sexual abuse. Child Adolesc Psychiatr Clin N Am 23: 321-337.

4. Keygnaert I, Guieu A (2015) What the eye does not see. A critical interpretive synthesis of European Union policies addressing sexual violence in vulnerable migrants. Reprod Health Matters 23: 45-55.

5. Seyran A (2009) Islam needs a sexual revolution. Ullstein publishing house, Berlin.

6. Lokhmatkina NV, Kuznetsova OY, Feder GS (2009) Prevalence and associations of partner abuse in women attending Russian general practice. Fam Pract 27: 625-631.

7. Behere PB, Mulmule AN (2013) Sexual abuse in 8-year-old child: Where do we stand legally? Indian J Psychol Med 35: 203-205.

8. Sufuoglu Z, Oral R, Aydin F, Cankardes B, Kandemirici B, et al. (2014) Epidemiological study of negative childhood experiences in three provinces of Turkey. Turk Pediatri Ars 49: 47-56.

9. UNHCR (2003) Sexual and gender-based violence against refugees, returnees and internally displaced persons.

10. UNHCR (2013) UNHCR Global Appeal 2013 Update: Populations of Concern. United Nations High Commissioner for Refugees, Geneva.

11. Refugee Commission (2016) Refugee Women and Girls in Germany and Sweden. Women's Refugee Commission, New York, USA.

12. Hossain M, Zimmerman C, Watts C (2014) Preventing violence against women and girls in conflict. Lancet 383: 2021-2022.

13. Keynaert I, Dias SF, Degomme O, Devillé W, Kennedy P, et al. (2015) Sexual and gender-based violence in the European asylum and reception sector: A perpetuum mobile? Eur Journal Public Health 25: 90-96.

14. Haug S, Müssig S, Stichs A (2009) Muslim life in Germany. BAMFForschungsbericht 6 . Nürnberg.

15. Bhugra D, Gupta S (2011) Migration and Mental Health, Cambridge University Press, New York, USA.

16. Kizilhan JI, Bermejo I (2009): Migration, culture and health. In: Bengel J, Jerusalem M (Hrsg, Eds): Handbook of Health Psychology and Medical Psychology, Göttingen. Hogrefe 509-518.

17. Lindert J, Schouler-Ocak M, Heinz A, Priebe S (2008) Mental health, health care utilization of migrants in Europe. Eur Psychiatry 23: 14-20.
18. Kirmayer LJ, Weinfeld M, Burgos G, Du Fort GG, Lasry JC, et al. (2007) Use of health care services for psychological distress by immigrants in an urban multicultural milieu. Can J Psychiatry 52: 295-304.

19. Bhugra D (2004) Migration and mental health. Acta Psychiatr Scand 109: 243-258.

20. Schouler-Ocak M (2015) Trauma and migration. Cultural factors in the diagnosis and treatment of traumatized immigrants. Springer, Berlin.

21. Uslucan H (2005) Life-world uncertainty of Turkish migrants. Psychosozial 28: 111-122.

22. Kizilhan JI (2011) Posttraumatic symptoms with young girls in the Iraq after a genital mutilation (FGM). Eur J Psychiat 7: 359-373.

23. Chirkov V, Ryan RM, Kim Y, Kaplan U (2003) Differentiating autonomy from individualism and independence: A self-determination perspective on internalization of cultural orientations, gender and wellbeing. J Pers Soc Psychol 84: 97-110.

24. Kizilhan JI (2014) Religious and cultural aspects of psychotherapy in Muslim patients from tradition-oriented societies. Int Rev Psychiatry 26: 335-343.

25. Butler EA, Gross JA (2009) Emotion and emotion regulation: Integrating individual and social levels of analysis. Emotion Review 1: 86-87.

26. Assion J (2005) Migration and mental illness. Migration und seelische Gesundheit pp: 133-144.

27. Haasen C, Yagdiran O (2001) Assessment of mental disorders in a multicultural society, Freiburg: Lambertus.

28. Kirkcaldy B, Wittig U, Furnham A, Merbach M, Siefen RG (2006) Health and migration. Psychosocial determinants. Federal Health Gazette Health Research Health Protection 49: 873-883.

29. Fontes LA, Plummer C (2010) Cultural issues in disclosures of child sexual abuse. J Child Sex Abus 19: 491-518.

30. Lima SH (2014) A critical examination of the effect of unrest conflict and violence on women and children. Islamic panacea. Muslim Community Centre (MCC), Nigeria.

31. Budhwani H, Hearld KR (2017) Muslim women's experiences with stigma, abuse, and depression: Results of a sample study conducted in the United States. J Womens Health 26: 435-441.

32. Kirmayer LJ, Narasiah L, Munoz M, Rashid M, Ryder AG, et al. (2011) Common mental health problems in immigrants and refugees: General approach in primary care. CMAJ 183: 959-967.

33. Ersoy N, Born MH, Derous E, Van der Molen HT (2011) Effects of workrelated norm violations and general beliefs about the world on feelings of shame and guilt: A comparison between Turkey and the Netherlands. AASP 14: 50-62.

34. Kizilhan JI (2017) Patient form middle east and the impact of culture on psychological pain-treatment. Fibrom Open Access 2: 1.

35. Ghorbani N, Watson PJ, Rezazadeh Z, Cunningham CJL (2011) Dialogical validity of religious measures in Iran: Relationships with integrative self-knowledge and self-control of the "Perfect Man" (Ensān-e Kāmel). Archive for the Psychology of Religion 33: 93-113.

36. Knipscheer JW, Drogendijk AN, Gülsen CH, Kleber RJ (2009) Differences and similarities in posttraumatic stress between economic migrants and forced migrants: Acculturation and mental health within a Turkish and a Kurdish sample. IJCHP 9: 373-391.

37. Pearce N, Foliaki S, Sporle A, Cunningham C (2004) Genetics, race, ethnicity and health. BMJ 328: 1070-1072.

38. Bienek S, Stadler L, Pfeiffer C (2011) First research report on the representative survey sexual abuse. Criminological Research Institute Lower Saxony.

39. Hodes M, Jagdew D, Chandra N, Cuniff A (2008) Risk and resilience for psychological distress amongst unaccompanied asylum seeking adolescents. J Child Psychol Psychiatry 49: 723-732.

40. Kizilhan JI (2017) Forced marriage and mental health by migrants in Germany. Arch Community Med Public Health 3: 071-076.

41. Fedeli U, Alba N, Lisiero M, Zambon F, Avossa F, et al. (2010) Obstetric hospitalizations among Italian women, regular and irregular immigrants in North-Eastern Italy. Acta Obstet Gynecol Scand 89: 1432-1437. 
Citation: Kizilhan JI (2017) Migration and Transcultural Aspect of Sexual Abuse of Children and Adolescents. J Trauma Treat 6: 408. doi: 10.4172/2167-1222.1000408

Page 7 of 7

42. Koch H, Kruck M (2009) I'll tell you anyway! "Prevention of sexual abuse in school (grades 1-10). Theory, Practice Reports, Literature Analysis, Materials.

43. Machleidt W, Calliess IT (2009) Treatment of migrants and transcultural psychiatry. In: Berger M (eds.): Mental illnesses. Urban \& Fischer Munich. pp. 1119-1143.

44. Ruf M, Schauer M, Neuner F, Catani C, Schauer M, et al. (2010) Narrative exposure therapy for 7- to 16-year old: A randomized controlled trial with traumatized refugee children. J Trauma Stress 23: 437-445.
45. Kainth GS (2010) Push and pull factors of migration: A case of brick kiln migrant workers in Punjab. Asia-Pacific Journal of Social Sciences 1: 82-116.

46. A Valuable Islam Collection (2013) Central Institute Islam Archive Germany, BAMF. 